\title{
ARTICLE OPEN The role of complement C5a receptor in DPSC odontoblastic differentiation and in vivo reparative dentin formation
}

\author{
Muhammad Irfan ${ }^{1}$, Ji-Hyun Kim ${ }^{1}$, Hassan Marzban ${ }^{2}$, David A. Reed $\mathbb{D}^{1}$, Anne George ${ }^{1}$, Lyndon F. Cooper ${ }^{1}$ and Seung Chung (D) $^{1 凶}$
}

Therapeutic dentin regeneration remains difficult to achieve, and a majority of the attention has been given to anabolic strategies to promote dentinogenesis directly, whereas, the available literature is insufficient to understand the role of inflammation and inflammatory complement system on dentinogenesis. The aim of this study is to determine the role of complement $\mathrm{C} 5 \mathrm{a}$ receptor (C5aR) in regulating dental pulp stem cells (DPSCs) differentiation and in vivo dentin regeneration. Human DPSCs were subjected to odontogenic differentiation in osteogenic media treated with the C5aR agonist and C5aR antagonist. In vivo dentin formation was evaluated using the dentin injury/pulp-capping model of the C5a-deficient and wildtype mice. In vitro results demonstrate that $\mathrm{C} 5 \mathrm{aR}$ inhibition caused a substantial reduction in odontogenic DPSCs differentiation markers such as DMP-1 and DSPP, while the C5aR activation increased these key odontogenic genes compared to control. A reparative dentin formation using the $\mathrm{C} 5 \mathrm{a}$-deficient mice shows that dentin regeneration is significantly reduced in the C5a-deficient mice. These data suggest a positive role of $\mathrm{C} 5 \mathrm{aR}$ in the odontogenic DPSCs differentiation and tertiary/reparative dentin formation. This study addresses a novel regulatory pathway and a therapeutic approach for improving the efficiency of dentin regeneration in affected teeth.

International Journal of Oral Science (2022)14:7

; https://doi.org/10.1038/s41368-022-00158-4

\section{INTRODUCTION}

Dental caries is one of the major health issues which affects the majority of the U.S. adult population. ${ }^{1}$ The severity of the carious injury determines the dentin-pulp complex response. For example, in case of a moderate injury, the surviving odontoblasts produce protective reactionary dentin beneath the injured site, ${ }^{2,3}$ while a serious injury may involve full or partial regeneration including vascularization, innervation, and dentin repairment endorsed by the generation of odontoblast-like cells. ${ }^{4}$ It causes severe pain if left untreated and requires endodontic therapy or may lead to permanent tooth loss. ${ }^{5}$ There could be several culprits behind caries; including bacterial invasion, proteolysis or physicochemical dissolution of teeth components, and direct interaction of bacteria or their toxins with dental pulp stem cells (DPSCs) and odontoblasts trigger a reparative process of tertiary dentin formation which further recruit and differentiate DPSCs. ${ }^{6}$

In clinical therapies, pulp-capping could be aimed to repair dentin and sustain its vitality which ultimately leads to the endurance of natural dentition. ${ }^{7}$ However, post infection, therapeutic dentin regeneration is unclear and the underlying mechanism staging the role of inflammation on dentinogenesis in dentin-pulp regeneration is to be elucidated.

The complement system, a key player of innate immunity and inflammation, is expressed and activated in the carious teeth. ${ }^{8}$ Beyond its role in immunity, the complement system participates in tissue regeneration of the liver, ${ }^{9}$ bone ${ }^{10}$, and cardiac tissues. ${ }^{11} \mathrm{C} 5 \mathrm{a}$ is the complement component active fragment activated from plasma proteins in response to injury. Since $\mathrm{C} 5 \mathrm{a}$ is a powerful chemotactic factor, it is involved in one of the early steps in dentin-pulp regeneration by recruitment of the immune cells and human pulp progenitor cells to the injured area. $^{12-14}$ It exerts its action by binding to the G-coupled protein receptor (GPCR) C5aR. ${ }^{15,16}$ Previously, we also demonstrated that complement C5aR activation is involved in two major processes of dentin-pulp regeneration: the pulp progenitor's migration to the injured $\operatorname{site}^{17,18}$ and the pulp nerve growth beneath carious injury. ${ }^{19-21}$

Very little information is available about the involvement of the complement in the tooth's response to the common infection, caries. Moreover, inflammatory complement C5a's role in caries-mediated dentin regeneration has received little recognition. We recently identified the role of $C 5 \mathrm{aR}$ and $\mathrm{C} 5 \mathrm{~L} 2$ in DPSCs odontoblastic differentiation under hypoxia and inflammatory context using $\mathrm{C} 5 \mathrm{aR}$ antagonist and $\mathrm{C} 5 \mathrm{~L} 2$ siRNA. ${ }^{22,23}$ Here, we further propose a significant role for the complement system and $\mathrm{C} 5 \mathrm{aR}$ in DPSCs odontoblastic differentiation by activating $\mathrm{C} 5 \mathrm{aR}$ and in vivo reparative dentin formation using the C5a-deficient mice.

\section{RESULTS}

Differentiating DPSCs express mesenchymal stem cell marker STRO-1 and C5a receptor

Human DPSCs were subjected to odontogenic differentiation using the osteogenic medium for 24 days. We have successfully set up in vitro DPSCs odontoblastic differentiation before. ${ }^{22,23}$ Figure $1 \mathrm{~b}-\mathrm{d}$ shows DPSCs differentiated into odontoblast-like cells at day 24 compared to differentiating DPSCs at day 4 (Fig. 1a) as 

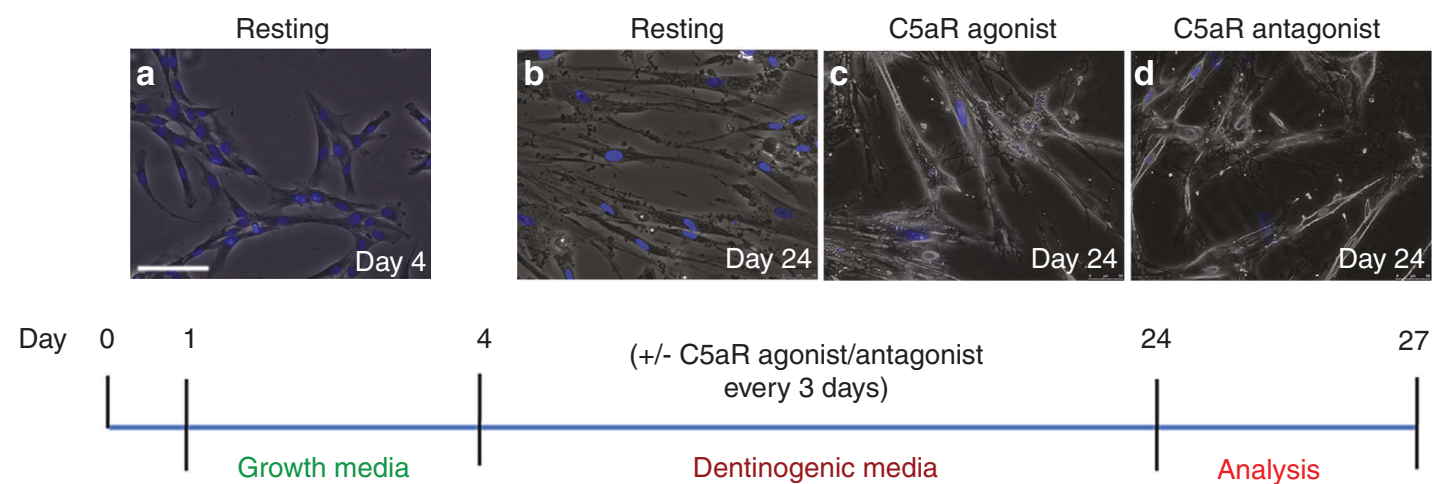
(+/- C5aR agonist/antagonist every 3 days)

24 27

Dentinogenic media STRO-1

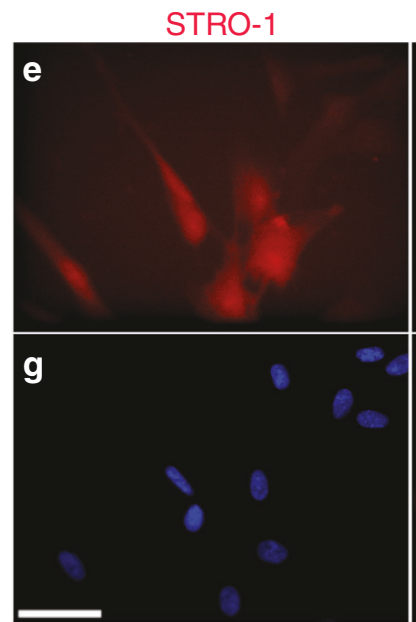

DAPI

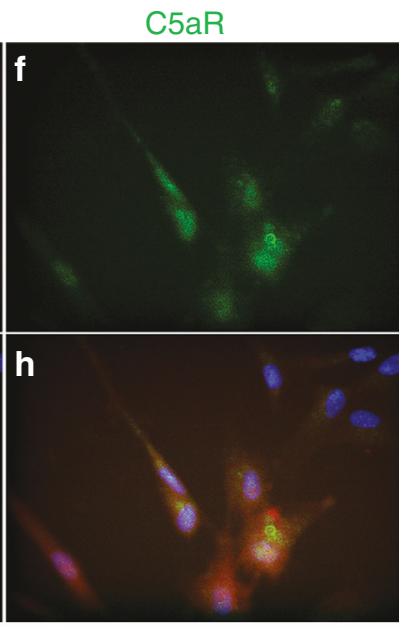

Merge

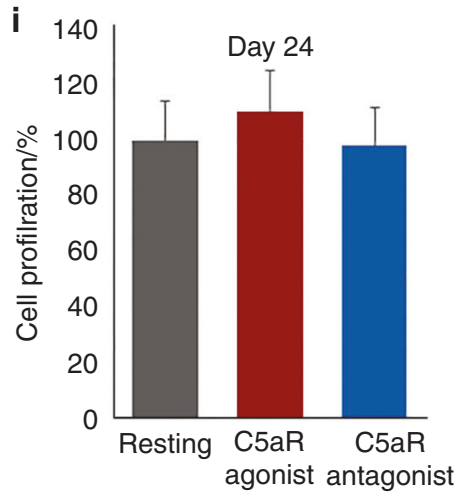

agonist antagonist

Fig. 1 A schematic timeline representation of odontogenic DPSCs differentiation. Commercially available DPSCs were acquired and confluent DPSCs were cultured in a regular growth media for 4 days. 2-4 passage of DPSCs were cultured at $5 \times 10^{4}$ cells per well concentration. Subsequently, cells were cultured in dentinogenic media and treated with a C5aR agonist or antagonist from the differentiation day 4 to day 24. The medium was replaced every 3 days. Representative images of differentiating DPSCs at day 4 (a) and day 24 (b-d). e-h Doubleimmunofluorescence staining with anti-STRO-1 (red channel) and C5aR (green channel) in DPSCs at day 4 confirms that C5a receptor-positive cells also express STRO-1. i Bar graph showing no. of differentiated cells as cell proliferation. Differentiated DAPI stained cells were counted using ImageJ software. Scale bars: $100 \mu \mathrm{m}(\mathbf{a}-\mathbf{d})$, and $50 \mu \mathrm{m}(\mathbf{e}-\mathbf{h})$

previously described by Baldion et al. ${ }^{24}$ and Huang et al. $^{25}$. The C5a receptor agonist and inhibitor W54011 were applied during differentiation at day 4 (a timeline in Fig. 1). The homogeneous population of DPSCs was examined with the co-localization of the mesenchymal stem cell marker STRO-1 (Fig. 1e). Our analysis confirms over $99 \%$ purity of DPSCs $(P<0.001)$. These cells have been validated in several recent publications. ${ }^{22,23,26}$ Previous studies revealed that human DPSCs express the $\mathrm{C} 5 \mathrm{aR} .{ }^{18}$ Consistent with these data, our immunofluorescent double staining data indicated that the STRO-1-positive DPSCs express the C5aR (Fig. 1e-h). No significant difference in the number of the cell population was observed among various treatments (Fig. 1i).

C5a receptor activation resulted in a significant increase in DSPP and DMP-1 expression in the differentiated cells from DPSCs

To identify the role of the complement receptor C5aR activation and blocking in the DPSCs odontoblastic differentiation, DPSCs were cultured and subjected to odontogenic differentiation for 3 weeks using dentinogenic media (Fig. 2). Cells were treated with complement $\mathrm{C} 5 \mathrm{a}$ receptor $(\mathrm{C} 5 \mathrm{aR})$ agonist or antagonist every three days.

The differentiated cells showed odontoblast-like properties as they expressed well-established odontogenic cell markers ${ }^{27,28}$ such as dentin matrix protein (DMP)-1 and dentin sialophosphoprotein (DSPP). The treatment of DPSCs with C5aR agonist significantly increased the expression of DSPP and DMP-1
(Fig. 2b, e). Immunofluorescence staining shows that C5aRagonist-stimulated DPSCs expressed significantly increased DSPP, and DMP-1 expression compared to resting cells, after 21 days of differentiation (Fig. 2j, k). Higher magnification shows the co-localization of DSPP and DMP-1 in the cytoplasm of DPSCs in C5aR-agonist treatment groups (Fig. 3b). Staining density of DSPP and DMP-1 was observed significantly higher (Fig. 3d, e; $p<0.001)$ in C5aR-agonist-treated cells $(221.8 \pm 33.7$ and $186.6 \pm 40.2$, respectively) compared with resting control $(100 \pm 21.4$ and $77.2 \pm 11.7)$. Taken together, these data suggest that $\mathrm{C} 5 \mathrm{aR}$ activation plays a key role in the modulation of DSPP and DMP-1 secretion, linking these key molecules to the mechanisms of action of $\mathrm{C} 5 \mathrm{aR}$.

C5a receptor blocking resulted in a decrease in DSPP and DMP-1 expression in the differentiated cells from DPSCs

Moderate inhibition of DSPP and DMP-1 expression was observed in C5aR-antagonist-treated cells (Figs. 2c, $\mathrm{f}, \mathrm{I}$ and $3 \mathrm{c}$ ), indicating the involvement of complement $\mathrm{C} 5 \mathrm{aR}$ in the expression of important proteins that help mineralization and development of hard dentin. The bar graph shows the fluorescence intensity between various treatment groups (Fig. 3d, e). Staining density of DSPP and DMP-1 significantly reduced (Fig. 3c; $P<0.001$ ) in C5aR-antagonist-treated cells ( $72.8 \pm 12.5$ and $54.8 \pm 22.9$, respectively) compared with the agonist-treated group ( $221.8 \pm 33.7$ and $186.6 \pm 40.2$, respectively), and it was even less than resting control cells. These results 

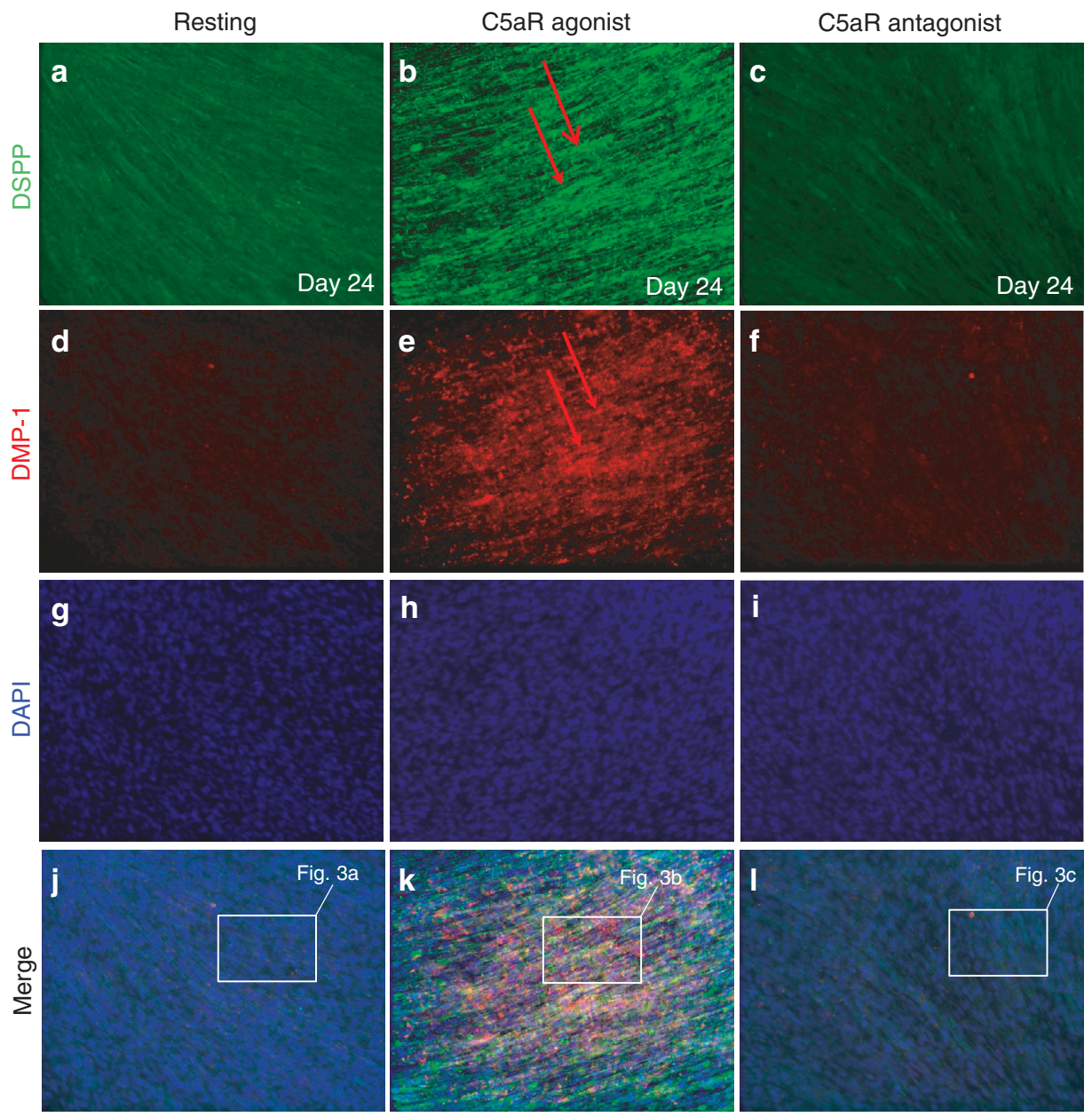

Fig. 2 Complement C5a receptor-mediated DSPP and DMP-1 expression after DPSCs odontoblastic differentiation. Immunofluorescence double staining was used to analyze DSPP and DMP-1 expression in C5aR-mediated DPSC differentiation. Anti-DSPP (green) and DMP-1 (red) were found co-localized in cytoplasm of DPSCs in C5aR-agonist-treated cells after 21 days of treatment (b, e, and $\mathbf{k})$. An intense staining was observed in C5aR-agonist-treated cells. For each condition, negative controls, performed by replacement of the DSPP and DMP-1 primary antibodies and secondary antibody used to detect DSPP was Alexa-488 (green; a-c) and DMP-1 through Alexa-594 (red; d-f); nuclei were counterstained with DAPI (blue; $\mathbf{g}-\mathbf{i}$ ). (j-l) Merged figures showing colocalization of DSPP and DMP-1 among resting, C5aR-agonist and C5aRantagonist treated DPSCs.

suggest the involvement of complement $\mathrm{C} 5 \mathrm{a}$ as a positive regulator in dentinogenesis.

In vitro stimulation of DPSCs with recombinant human $\mathrm{C} 5 \mathrm{a}$ has no effect on the expression of DSPP

Our previous studies showed that recombinant $\mathrm{C} 5 \mathrm{a}$ protein had no effect on the pulp fibroblast-mediated brain-derived nerve growth factor $^{19}$ and nerve growth factor secretion, ${ }^{21}$ we next determined whether exogenous $\mathrm{C} 5 \mathrm{a}$ treatment influences the DSPP expression on DPSCs. Double-immunofluorescence-labeled staining for antiDSPP and anti-DMP-1 during early differentiation shows that DSPP and DMP-1 were weakly co-localized in the cytoplasm of DPSCs in C5a-treated cells (Fig. 4a-f). Real-time PCR analysis of DSPP mRNA expression at day 10 by DPSCs demonstrates early and continued induction during odontoblastic differentiation (Fig. 4g). Treatment of DPSCs using the recombinant human C5a protein does not affect the basal level of DSPP expression but significantly increased with $\mathrm{C} 5 \mathrm{aR}$-agonist treatment (Fig. $4 \mathrm{~g}-\mathrm{C} 5 \mathrm{aR}$ agonist: $2.78 \pm 0.24$ vs $\mathrm{C} 5 \mathrm{aR}$ antagonist: $0.68 \pm 0.049$ vs $\mathrm{C} 5 \mathrm{a}$ protein: $1.16 \pm 0.21 ; P<0.01 ; P<0.001)$. Similarly, C5aR-agonist treatment significantly increased the mRNA levels of DSPP and DMP-1 at day 24 (Fig. 4h; $P<0.05 ; P<0.01$ ) while $C 5 a R$-antagonist inhibited them (Fig. 4h; $P<0.001$ ), without affecting C5aR expression level (Fig. 4i).
C5a deficiency reduces the regenerative dentin formation of injured teeth

To identify in vivo role of $\mathrm{C} 5 \mathrm{a}$ in reparative dentin formation, we utilized wild-type and $\mathrm{C} 5 \mathrm{a}$-deficient mice. The targeted disruption of the C5a gene was described previously. ${ }^{29}$ To induce dentin injury to wild-type (WT) mice (Fig. 5), the burr exposed the dentine/pulp, and a hypodermic needle was used to further punch the pulp. The exposed dentin/pulp was sealed with mineral trioxide aggregate (MTA) to protect the pulp from further inflammation (Fig. 5b). Animals were sacrificed after 4 weeks of the initial injury, and the mandibles were removed. Histological and immunofluorescence staining was performed to evaluate the importance of complement system activation in dental pulp response to carious injuries. After $24 \mathrm{~h}$ of the injury, C5aR expression is significantly increased in dental pulp (Fig. $5 f, g$ ) compared to control (Fig. 5e).

The reparative/tertiary dentin formation in the teeth of WT mice was evaluated through the light microscopy observation of H\&E-stained sections (Fig. 5c, d). The serial sections of the whole teeth were sectioned with a thickness of $15 \mu \mathrm{m}$ and stained and collected to reveal its overall pattern. Also, a micro-CT analysis was performed to quantitatively measure the regenerated dentin volume and mineral density. Representative micro-CT images (Fig. 6a-f) and H\&E-stained sections (Fig. 6g, h) of C5a-deficient 


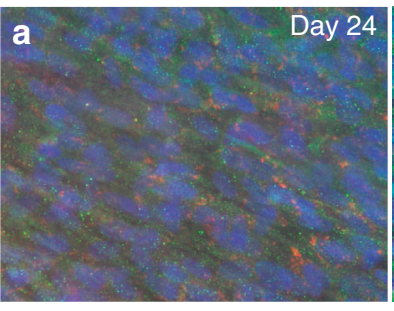

Resting

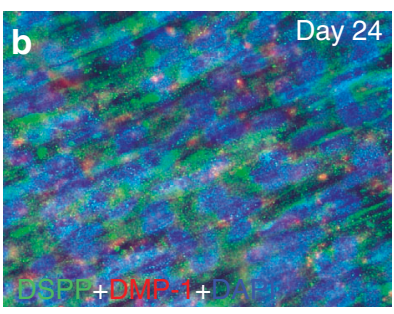

C5aR agonist

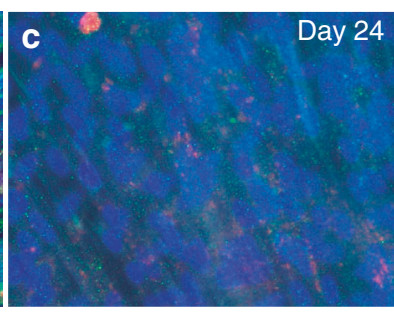

C5aR antagonist d

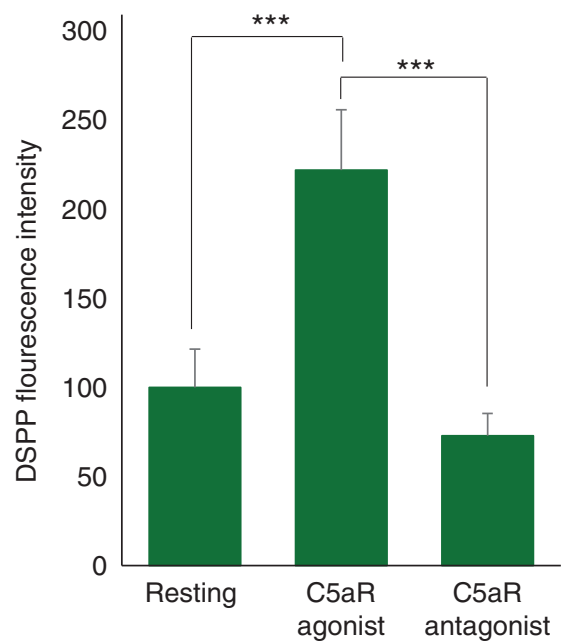

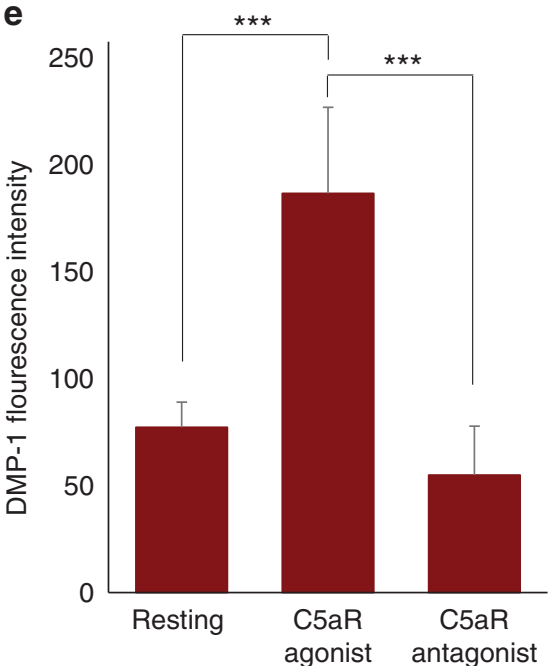

Fig. 3 DPSC-derived odontoblastic cells express more DSPP and DMP-1 under C5aR agonist treatment. a-c Magnified pictures (a-c) from the respective boxes of Fig. 2. Anti-DSPP (green) and DMP-1 (red) immune intensities are significantly higher in the C5aR agonist treatment group (b) compared to resting (a) and C5aR antagonist treatment (c) groups. d, e Bar graphs showing the fluorescence intensity of DSPP and DMP-1 in various treatment groups. C5aR stimulation by C5aR agonist specifically increases DSPP (d) and DMP-1 (e) expression in DPSCs undergoing odontoblastic differentiation (gray versus red lines). ${ }^{* *} P<0.001$ vs untreated control of resting cells $(n=3)$.

mice teeth and quantitative calculations (Fig. 6i) of dentin regeneration show less mineralization in the C5a-deficient mice after 4 weeks of recovery. The decrease is statistically significant-Tissue Mineral Density (TMD): $\mathrm{C}^{2} \mathrm{a}^{+/+}: 1453 \pm 78$ vs C $5 \mathrm{a}^{-/-}: 1093 \pm 111.3$; Total mg: ${\mathrm{C} 5 \mathrm{a}^{+/+}}^{+1} 0.022 \pm 0.002$ vs $\mathrm{C}^{-1-} \mathrm{a}^{-/}$: $0.016 \pm 0.001$. Taken together, our comprehensive analyses demonstrate that $\mathrm{C} 5$ a deficiency resulted in a decreased dentin regeneration suggesting the C5a's key in vivo role in reparative dentin formation.

\section{DISCUSSION}

Inflammation, which is a natural host response to infection/ injury, is known to control dentinogenesis both positively and negatively. It facilitates the pulp progenitor cell's migration, proliferation, and odontoblastic differentiation. 8,17,18 However, uncontrolled inflammation can cause irreversible damages to the tissue. Clearly, bacteria and their toxins influence odontoblasts during advanced caries affecting dentin. ${ }^{30}$ New odontoblast-like cells could help in dentin repair for subsequent regeneration, ${ }^{12,31}$ but this complex regenerative process is mainly associated with DPSCs and their key factors involved in activation and differentiation. $^{8}$ Literature has suggested that dentin extracellular matrix molecules or some growth factors i.e., transforming growth factor beta- 1 or basic fibroblast growth factor which produced because of acid dissolution of dentin, are responsible for dentin regeneration following caries or dentin infection. ${ }^{18,19,32,33}$ However, it remains unclear how regenerative signals are linked to inflammation and trauma.

We and others recently identified complement system activation, a central and early response to tissue damage, as an additional source of regeneration signals for dentin regeneration subsequent to carious injuries. ${ }^{8,19}$ One of the most critical components of innate immunity and inflammation is the complement system which can be activated by multiple factors like apoptosis, necrosis, or some pathogen-associated molecular patterns. ${ }^{34-36}$ Such events could be observed during caries. Carious injuries trigger the complement system by cytolytic membrane attack complex formation in human third molars. ${ }^{17,18}$ This is considered among the most effective initial responses against pathogens and altered host cells ${ }^{37}$ including the recruitment of immune cells due to the production of important anaphylatoxin $\mathrm{C} 5 \mathrm{a}$ and some opsonins like $\mathrm{C} 5 \mathrm{~b} .{ }^{38}$ Beyond its role in immunity, the complement system participates in tissue regeneration of the liver, ${ }^{9}$ bone ${ }^{10}$, and cardiac tissues. ${ }^{11}$ Recently, our lab has established that complement system activation in two critical steps of dentin regeneration: recruitment of pulp progenitor cells to the site of injury ${ }^{17,18}$ and the pulp nerve growth beneath carious injury. ${ }^{19-21}$ However, there are a lack of studies that implicate the complement activation system in the odontoblastic differentiation of DPSCs and tertiary dentin formation or regeneration in response to caries. Here we have explored this phenomenon in cell culture and animal models, and we demonstrate that C5aRs expression is elevated in inflamed pulp tissue.

Our findings supporting a key role for the complement $\mathrm{C} 5 \mathrm{a}$ receptor in DPSC odonto-lineage differentiation and in vivo dentin regeneration are supported by a recent study where Bergmann et al., ${ }^{39}$ explained the linkage between inflammation and dental tissue regeneration through complement activation. Previous studies have explored the differentiating potential of DPSCs into odontoblast-like cells by confirming their genotypic expressions 

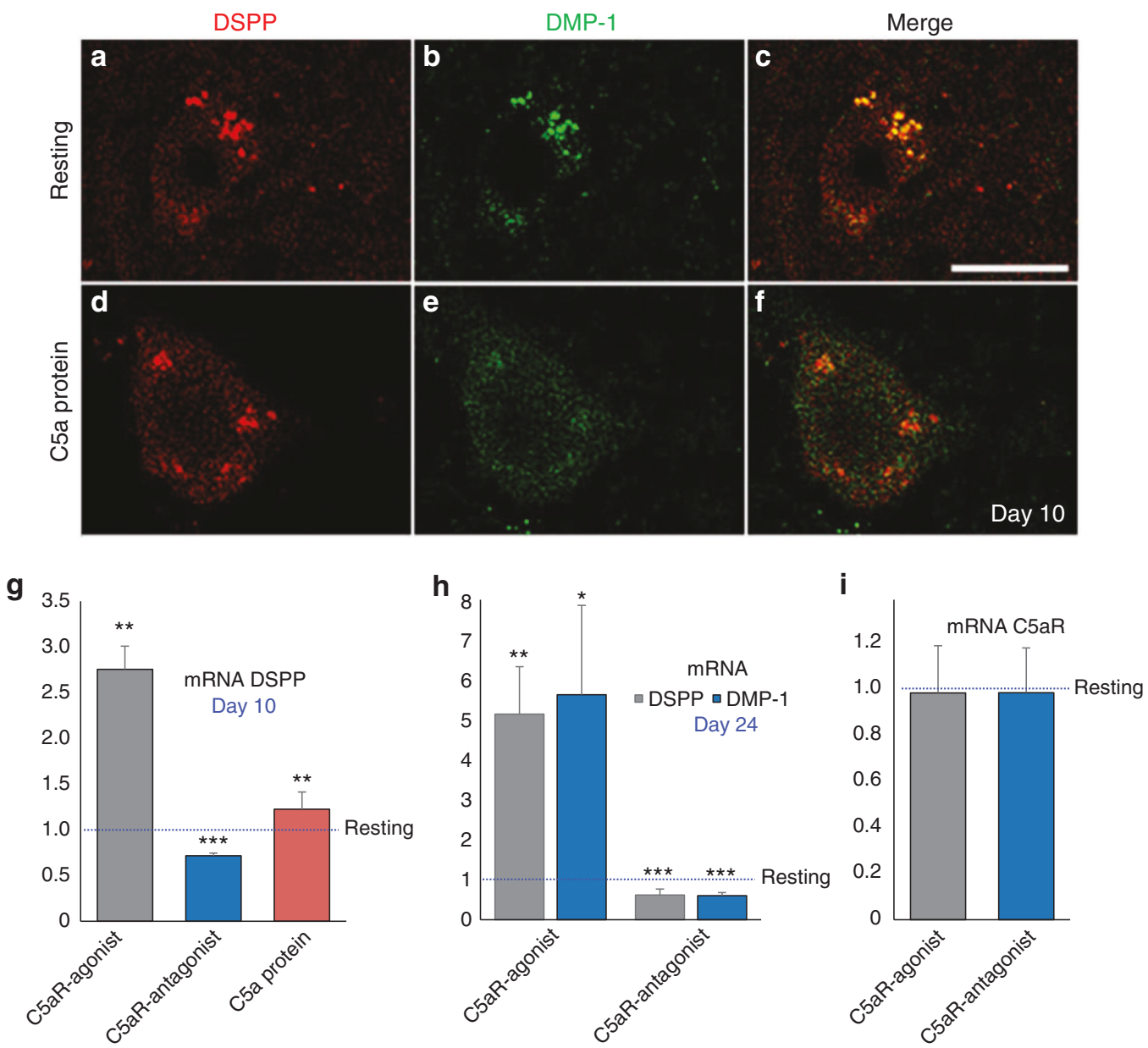

Fig. 4 Effect of exogenous C5a on DSPP and DMP-1 expression and PCR analysis of DPSC-derived odontoblast-like cells. a-f Immunofluorescence double staining was used to analyze DSPP and DMP-1 expression in exogenous C5a-mediated DPSCs at day 10. Anti-DSPP (red) and DMP-1 (green) were found weakly co-localized in the cytoplasm of DPSCs in C5a-treated cells without any significant difference compared with resting control. Scale bar: $25 \mu \mathrm{m}$. g, h Real-time PCR analysis of DSPP and DMP-1 in the C5aR agonist, C5aR antagonist, and C5a recombinant protein treatment groups compared to control (calculated ' 1 ' value of respective genes expression). The analysis reveals a significant upregulation of DSPP and DMP-1 mRNA expression in the C5aR agonist treatment group. Treatment of DPSCs using the recombinant human C5a protein does not affect the basal level of DSPP expression. i C5aR mRNA expression between resting cells and $\mathrm{C} 5 \mathrm{aR}$-agonist or antagonist-treated cells. C5aR-agonist or antagonist treatment do not induce a C5aR mRNA expression change

and phenotypic characteristics using DSPP and DMP-1 immunofluorescence staining. ${ }^{24,25}$ Similar attributes were observed in our study (Figs. 1 and 2). DSPP and DMP-1 are expressed in differentiating odontoblasts and are essential proteins for dentin formation by enhancing mineralization. ${ }^{40}$ Further, the differentiated DPSC's showed odontoblast-like phenotype as they expressed well-established odontogenic cell markers DMP-1 and DSPP (Figs. 2 and 3), yet at reduced levels in the presence of W54011, indicating the direct involvement of complement C5a proteins. Matsui et al. ${ }^{41}$ has revealed the role of DSPP and DMP-1 in CD146-positive DPSC mediated dentin-pulp regeneration. Dentin regeneration is a complex process involving many biological pathways. For example, Volponi et al. ${ }^{42}$ has reported the Wnt signaling pathway and its importance for odontoblastic differentiation and reparative dentin formation. Their group observed that OCN-Cre;Wls ${ }^{\mathrm{f} / \mathrm{fl}}$ transgenic mice exhibited stronger DSPP expression in odontoblasts and pulp, and denser dentin formation ${ }^{43}$ due to reduced Wnt signaling. Another published study showed that DSPP might be a downstream signaling effector to the DMP-1 in dentinogenesis using transgenic mice. ${ }^{44}$ $D^{\prime}$ Souza et al. ${ }^{45}$ has evaluated the in vivo developmental functions of DSPP and DMP-1 and concluded that DSPP and DMP-1 play a distinct role in the dentin matrix and their expression is evident throughout the process of odontogenesis. Our results show that treatment of DPSC with C5aR agonist significantly increased the DSPP and DMP-1 expression (Figs. 2 and 3). This is the first study showing that $\mathrm{C} 5 \mathrm{aR}$ activation in DPSCs could lead to a significant amount of dentin formation. This observation was consistent with our in vivo dentin regeneration in wild-type mice (Fig. 5) and the study using C5a-deficient mice (Fig. 6).

Previously, we designed a modified and choreographed microenvironment and established that dentin-pulp regeneration is a locally regulated process. ${ }^{4,8}$ Botero et al. ${ }^{46}$ has identified odontoblasts as a source of regeneration signals in caries but deep injuries may lead to the disintegration of odontoblasts at the injured area. ${ }^{12}$ Chmilewsky et al. ${ }^{22}$ has stated that C5a stimulation did not affect the expression of DMP-1 in DPSCs. Similarly, we did not find any effect of recombinant C5a on DSPP expression. Previously, our group has also reported that human pulp cells interact with the recombinant $\mathrm{C}_{5} \mathrm{a}^{18}$ and also demonstrated that human pulp progenitor cells bind the $\mathrm{C} 5 \mathrm{a}$ generated by the complement system activation from pulp fibroblast-produced proteins after LPS stimulation. ${ }^{47}$ To explore the role of C5a and to see whether the inflammation could affect the complement activation and at injured pulp, we studied C5a-deficient mice. Here, we observed that the complement system is activated in 

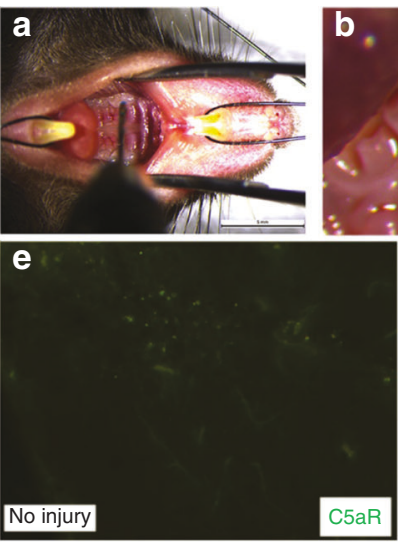
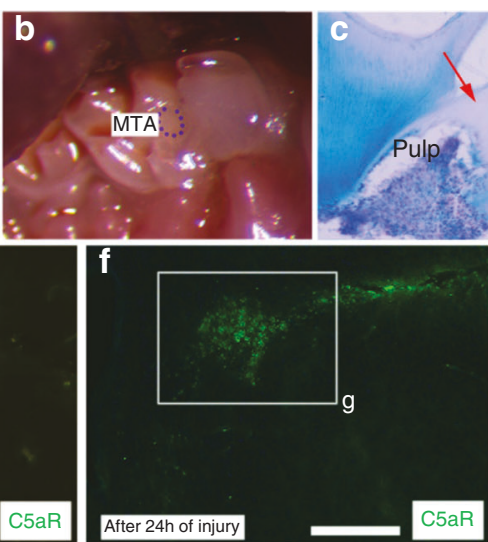
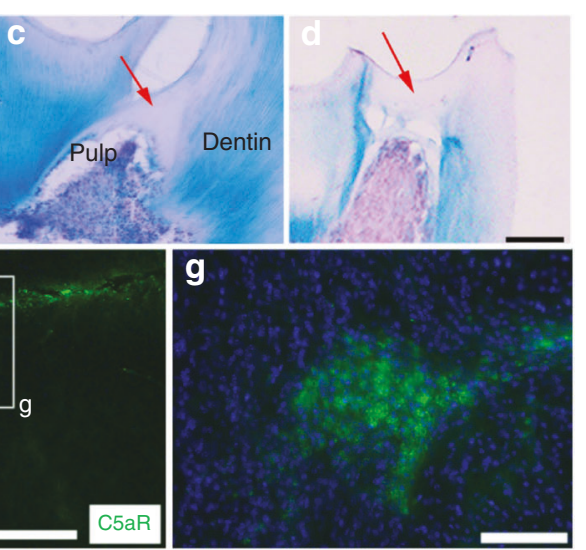

Fig. $5 \mathrm{C} 5 \mathrm{aR}$ expression increased in injured teeth of wild-type mice. $\mathbf{a}, \mathbf{b} 0.3 \mathrm{~mm}$ drill tip was used to puncture the dentin until the upper surface of the pulp, and shortly after, the injured area was capped with MTA. Scale bar: $5 \mathrm{~mm}$. c, d Hematoxylin and eosin staining showed a reparative dentin formation in the control mice (red arrows) after 4 weeks of recovery. Scale bar: $250 \mu \mathrm{m}$. e-g Immunofluorescence labeling for $\mathrm{C} 5 \mathrm{aR}$ (green) reveals that after $24 \mathrm{~h}$ of the injury, C5aR expression is significantly increased in the injured area (f; Scale bar: $250 \mu \mathrm{m}, \mathbf{g}$; Scale bar: $50 \mu \mathrm{m}$.) compared to control (e)

mouse teeth under the influence of carious injury which is directly proportional to the severity of injury while the inflammation was also weakly triggered in the C5a-deficient mice lacking complement system activation. It is well-known fact that there is a strong linkage between dental tissue regeneration and inflammation. ${ }^{39}$ Thus, the reduced inflammation in $\mathrm{C} 5 \mathrm{a}$-deficient mice might have decreased both odontogenesis and tertiary/reparative dentin formation (Figs. 5 and 6). In our unpublished observation, we have confirmed that LPS-induced inflammation potentiates C5aRmediated dentinogenesis and this is p38 protein kinasedependent. Taken together, our results confirmed that C5aR has a positive regulatory role in odontogenic DPSCs differentiation and reparative dentin formation.

It has long been established that DPSCs have a high regeneration capacity. Dentin regeneration is the key factor for maintaining tooth preservation following infection or injury. We believe that still there is a lot to explore about the involvement of complement system activation and its relation to bone and tissue regeneration. Understanding the biological mechanisms of odontogenesis/dentinogenesis and the role of inflammation in this process are required for successful DPSC engineering strategies. The scientific knowledge obtained from this study provides a foundation for creating therapeutic tools that target DPSC during dentin-pulp complex regeneration.

\section{MATERIALS AND METHODS}

Chemicals and reagents

Human dental pulp stem cells (DPSCs) were purchased from Lonza, Pharma \& Biotech (Cat. \# PT-5025). C5aR antagonist - W54011 was acquired from MilliporeSigma (Cat. \# 234415; Billerica, MA, USA) and C5aR agonist from Anaspec (Cat. \# AS-65121; Fremont, CA, USA). MEM-alpha, PBS, fetal bovine serum, L-glutamine, and Antibiotic-Antimycotic were procured from $\mathrm{Gibco}^{\mathrm{TM}}$ Fisher Scientific (Waltham, MA, USA). Poly-D-Lysine coated (BioCoat ${ }^{\mathrm{TM}}, 12 \mathrm{~mm}$ ) round German glass coverslips slips were purchased from Corning $^{\text {TM }}$ Fisher Scientific (Cat. \# 354087; Waltham, MA, USA). Various antibodies were procured: anti-C5a receptor (Cat. \# 213161-AP; Proteintech, ST. Louis, MO, USA), mouse anti-DMP-1 (Cat. \# SAB14002752; R\&D System/Sigma, ST. Louis, MO, USA), mouse antiSTRO-1 (Cat. \# sc-47733; Santa Cruz, Dallas, Texas, USA), mouse anti-DSPP (Cat. \# sc-73632; Santa Cruz, Dallas, Texas, USA).

Animals

Male C57BL/6, C5a-deficient mice aged 6-7 weeks and weighing 20-22 g were purchased from Jackson laboratory (Cat. \#000461).
The mice were acclimatized for 1 week in an air-conditioned room with a $12 \mathrm{~h} / 12 \mathrm{~h}$ light/dark cycle at a temperature and humidity of $22^{\circ} \mathrm{C} \pm 2{ }^{\circ} \mathrm{C}$ and $55 \% \pm 10 \%$, respectively, before further experimentation.

\section{Cell culture}

Commercially available human DPSCs, which were guaranteed through 10 population doublings, to express CD105, CD166, CD29, CD90, and CD73, and to not express CD34, CD45, and CD133; were further evaluated by immunocytochemistry in cultures with the STRO-1, a stem cell marker. Our analysis confirms that over $99 \%$ of cells $(n=5)$ used for our study were DPSCs. DPSCs were cultured at $37^{\circ} \mathrm{C}$ and $5 \% \mathrm{CO}_{2}$ in regular/osteogenic media and treated with C5aR antagonist - W54011 $\left(10 \mathrm{nmol} \cdot \mathrm{L}^{-1}\right)$ or C5aR agonist $\left(20 \mathrm{nmol} \cdot \mathrm{L}^{-1}\right)$ for $72 \mathrm{~h}$ in regular growth media (a MEM containing $10 \%$ fetal bovine serum (FBS), 1\% L-glutamine and antimycotic/ antibiotic), and then swapped with osteogenic media (a MEM containing $20 \%$ FBS, $1 \%$ L-glutamine and antimycotic/antibiotic, supplemented with $100 \mu \mathrm{g} \cdot \mathrm{mL}^{-1}$ ascorbic acid, $10 \mathrm{mmol} \cdot \mathrm{L}^{-1}$ $\beta$-glycerophosphate and $10 \mathrm{mmol} \cdot \mathrm{L}^{-1}$ dexamethasone) for 21 days and treated every three days with agonist or antagonist. The medium was changed every $2-3$ days. The whole differentiation experiments were conducted with different sets of DPSCs (between 2nd and 4th passages) 3 times, and cell proliferation was measured by counting the total number of cells.

\section{Real-time PCR}

DPSCs were cultured according to the differentiation protocol mentioned above in 6 wells plate with triplicates at $5 \times 10^{4}$ cells per well concentration for the treatment of the C5a receptor agonist or inhibitor W54011. Total mRNA was extracted with $0.8 \mathrm{~mL}$ Trizol (Invitrogen, Waltham, MA, USA) and analyzed using the Fisher Scientific NanoDrop 2000 device. The cDNA samples were analyzed using the Applied Biosystems SYBR green reagent system according to the manufacture protocol. Primer sequence of DSPP; forward: 5'-CTG TTG GGA AGA GCC AAG ATA AG-3', reverse: $5^{\prime}$-CCA AGA TCA TTC CAT GTT GTC CT-3'.

\section{Immunohistochemistry}

Mice teeth were fixed and routinely processed as previously described. ${ }^{14}$ Paraffin-embedded tissues were sectioned from intact and carious teeth and deparaffinized with xylene and graded ethanol. Some sections were hematoxylin-eosin-stained. For others, an antigen retrieval was performed at $98^{\circ} \mathrm{C}$ for $20 \mathrm{~min}$ in Tris $1 \mathrm{mmol} \cdot \mathrm{L}^{-1}$ per $0.1 \mathrm{mmol} \cdot \mathrm{L}^{-1}$ EDTA/0.5\% Tween, $\mathrm{pH} 6.0$ and nonspecific binding sites were blocked with $0.25 \%$ casein in PBS 

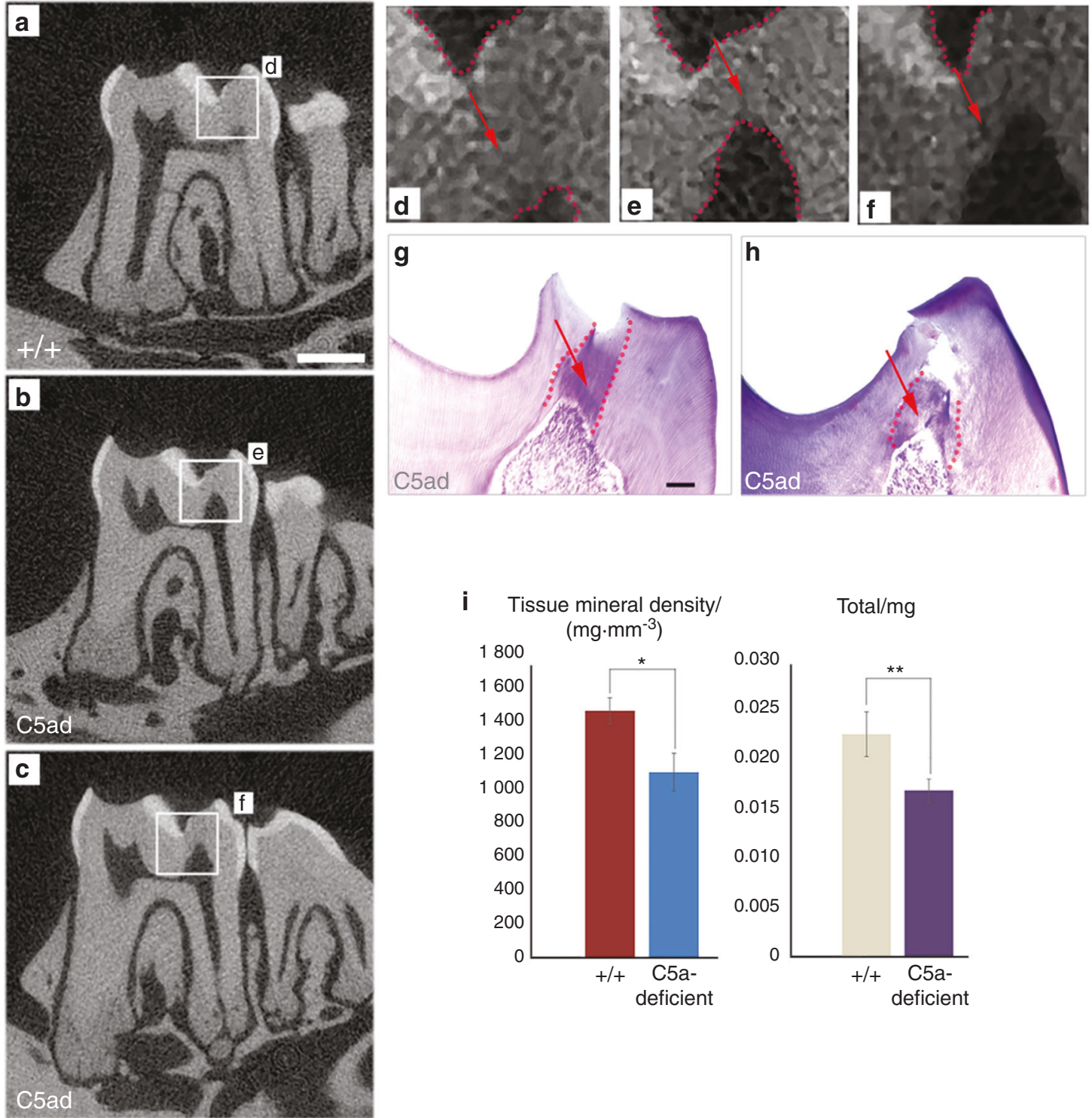

i Tissue mineral density/ $\left(\mathrm{mg} \cdot \mathrm{mm}^{-3}\right)$
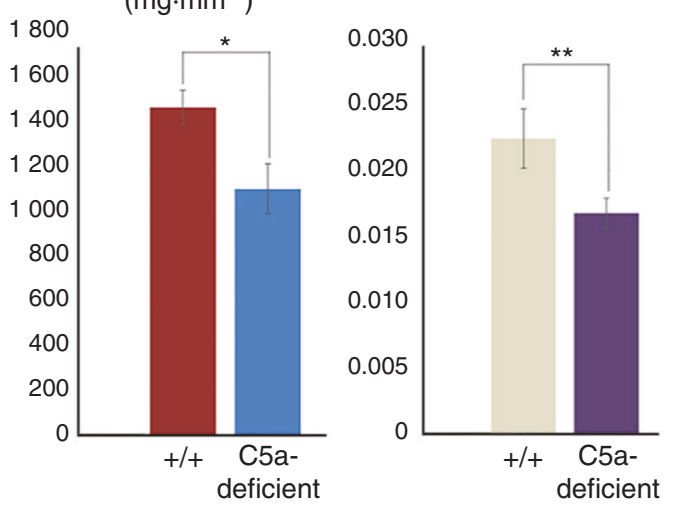

Fig. 6 In vivo dentin regeneration in the C5a-deficient mice after dentin injury/pulp-capping. a-c Representative Micro-CT images of upper molars obtained from C5a-deficient (C5ad) mice (b, c) and respective control (a) after 4 weeks of dentin injury. Scale bar: $0.5 \mathrm{~mm}$. $\mathbf{d}-\mathbf{f}$ The rectangle area of $\mathbf{a}, \mathbf{b}, \mathbf{c}$ is magnified in $\mathbf{d}$, e, and $\mathbf{f}$. Reparative dentin (red arrows) was observed after 4 weeks of recovery. C5a-deficient mice show a decreased dentin regeneration compared to the wild-type controls. $\mathbf{g}-\mathbf{h}$ H\&E staining of C5a-deficient (C5ad) mice shows delayed and defective dentin formation. i Quantitative calculation of dentin regeneration in the C5a-deficient mice. Tissue mineral density and Total mg of regenerated volume is statistically analyzed. Mineral formation analysis at the regeneration area shows that C5a-deficient mice form less mineral than the control. ${ }^{*} P<0.05,{ }^{* *} P<0.01$. Scale bar: $100 \mu \mathrm{m}$

for $15 \mathrm{~min}$ at room temperature. Then tooth sections were probed with primary antibodies with mouse anti-human C5aR $\left(20 \mu \mathrm{g} \cdot \mathrm{mL}^{-1}\right)$ or their respective isotype control for $1 \mathrm{~h}$ at room temperature and secondary antibody for $45 \mathrm{~min}$ with Alexa Fluor488 rabbit anti-mouse IgG $\left(2 \mu \mathrm{g} \cdot \mathrm{mL}^{-1}\right)$, and DAPI $\left(1 \mu \mathrm{g} \cdot \mathrm{mL}^{-1}\right)$ counterstain for fluorescence microscopy. Diaminobenzidine (DAB, $0.5 \mathrm{mg} \cdot \mathrm{mL}^{-1}$ ) was used to visualize the reaction.

\section{Immunofluorescence staining}

Differentiating and differentiated DPSCs were fixed and permeabilized as previously described. ${ }^{19,21}$ Subsequently, cells were incubated overnight with rabbit anti-C5a receptor (1:200), mouse anti-DMP-1 (1:1 000), mouse anti-STRO-1 (1:200), mouse anti-DSPP (1:500) or their respective control/isotypes. Later, the cells were treated with secondary antibody for $3 \mathrm{~h}$ with a mix of Alexa Fluor594 anti-mouse IgG, Alexa Fluor-488 anti-rabbit $\operatorname{lgG}\left(1 \mu \mathrm{g} \cdot \mathrm{mL}^{-1}\right)$, and/or DAPI $\left(2 \mu \mathrm{g} \cdot \mathrm{mL}^{-1}\right)$. The coverslips were mounted, and images were taken using a Zeiss Axiovert microscope. Fluorescence density was quantified using ImageJ $1.49 \mathrm{v}$ software and values were analyzed for statistical significance by SAS 9.4.

In vivo dentin regeneration

Male C57BL/6 C5a-deficient mice were purchased from Jackson laboratory (\#000461). Mice homozygous for the targeted mutation are viable, fertile, normal in size, and do not display any gross physical or behavioral abnormalities. A $0.3 \mathrm{~mm}$ rounded carbide burr drill with an automatic speed was applied to penetrate the dentin of the mouse upper first molar (only left side, the right side was used as a control). Once the burr exposes the dentine/pulp, an $11 \mathrm{G}$ needle was used to further punch the pulp. The exposed dentin/pulp was sealed with mineral trioxide aggregate (MTA) to protect the pulp from further inflammation. 
Animals were sacrificed starting after 4 weeks of the initial injury and the mandibles removed. ${ }^{48-51}$ The molars were examined and scored for smooth surface caries.

Data analysis

The statistical analysis was performed on at least 3 independent experiments with duplicates or triplicates, and statistical significance was determined using the student's $t$-test (SAS 9.4) to compare the different treatments and their respective controls $(P$-value $<0.05$ or less was considered statistically significant). For quantification of immunofluorescence staining intensity, ImageJ $1.49 \mathrm{v}$ software was used. Fixed areas of $1 \mathrm{~mm} \times 1 \mathrm{~mm}$ or $2 \mathrm{~mm} \times 2 \mathrm{~mm}$ were selected to analyze the number or fluorescence intensity of differentiated cells. Micro-CT analyses were performed using the RUSH hospital's commercial service to quantitatively measure the regenerated dentin volume. All animal phenotype analyses were blinded by examiners to avoid the examiner's preferences or expectations.

\section{ACKNOWLEDGEMENTS}

This study was supported by the NIH/NIDCR grants: R03 DE028637 - SC, R56 DE029816 - SC.

\section{AUTHOR CONTRIBUTIONS}

M.I. and J.-H.K. contributed to in vitro and in vivo experiments, data acquisition, analysis, interpretation, and drafted the manuscript. M.I., D.A.R., and H.M. performed animal experiments, figure organization, molecular work, and critically revised the manuscript. A.G., L.F.C., and S.C. contributed to conception, design, in vivo experiment, financial support, supervision of the results, and critically revised the manuscript.

\section{ADDITIONAL INFORMATION}

Competing interests: The authors declare no competing interests.

Ethics: All experiments were conducted according to Institutional Animal Care and Use Policy and approved by the IRB Protocol Committee at the University of Illinois at Chicago (Permit number: 19-022).

\section{REFERENCES}

1. Islam, B., Khan, S. N. \& Khan, A. U. Dental caries: from infection to prevention. Med. Sci. Monit. 13, RA196-RA203 (2007).

2. Chogle, S. M., Goodis, H. E. \& Kinaia, B. M. Pulpal and periradicular response to caries: current management and regenerative options. Dent. Clin. 56, 521-536 (2012).

3. Couve, E., Osorio, R. \& Schmachtenberg, O. Reactionary dentinogenesis and neuroimmune response in dental caries. J. Dent. Res. 93, 788-793 (2014).

4. About, I. Dentin regeneration in vitro: the pivotal role of supportive cells. $A d v$. Dent. Res. 23, 320-324 (2011).

5. Edwards, P. C. \& Kanjirath, P. Recognition and management of common acute conditions of the oral cavity resulting from tooth decay, periodontal disease, and trauma: an update for the family physician. J. Am. Board Fam. Med. 23, 285-294 (2010).

6. Conrads, G. Caries Excavation: Evolution of Treating Cavitated Carious Lesions Vol. 27, 1-10 (Karger Publishers, 2018).

7. Ahmed, G. M. et al. Cell-based transplantation versus cell homing approaches for pulp-dentin complex regeneration. Stem Cells Int. 2021, 8483668 (2021).

8. Chmilewsky, F., Jeanneau, C., Dejou, J. \& About, I. Sources of dentin-pulp regeneration signals and their modulation by the local microenvironment. J. Endod. 40, S19-S25 (2014).

9. Mastellos, D., Papadimitriou, J. C., Franchini, S., Tsonis, P. A. \& Lambris, J. D. A novel role of complement: mice deficient in the fifth component of complement (C5) exhibit impaired liver regeneration. J. Immunol. 166, 2479-2486 (2001).

10. Ignatius, A. et al. Complement $\mathrm{C} 3 \mathrm{a}$ and $\mathrm{C} 5 \mathrm{a}$ modulate osteoclast formation and inflammatory response of osteoblasts in synergism with IL-1ß. J. Cell. Biochem. 112, 2594-2605 (2011).

11. Lara-Astiaso, D. et al. Complement anaphylatoxins C3a and C5a induce a failing regenerative program in cardiac resident cells. Evidence of a role for cardiac resident stem cells other than cardiomyocyte renewal. Springerplus 1, 1-15 (2012).

12. Fitzgerald, M., Chiego, D. Jr \& Heys, D. Autoradiographic analysis of odontoblast replacement following pulp exposure in primate teeth. Arch. Oral. Biol. 35, 707-715 (1990).

13. Klos, A. et al. The role of the anaphylatoxins in health and disease. Mol. Immunol. 46, 2753-2766 (2009).

14. Téclès, O. et al. Activation of human dental pulp progenitor/stem cells in response to odontoblast injury. Arch. Oral. Biol. 50, 103-108 (2005).

15. Monk, P. N., Scola, A. M., Madala, P. \& Fairlie, D. P. Function, structure and therapeutic potential of complement C5a receptors. Br. J. Pharm. 152, 429-448 (2007).

16. Laursen, S. et al. Structure, function and control of complement $\mathrm{C} 5$ and its proteolytic fragments. Curr. Mol. Med. 12, 1083-1097 (2012).

17. Chmilewsky, F., Jeanneau, C., Laurent, P. \& About, I. Pulp fibroblasts synthesize functional complement proteins involved in initiating dentin-pulp regeneration. Am. J. Pathol. 184, 1991-2000 (2014).

18. Chmilewsky, F., Jeanneau, C., Laurent, P., Kirschfink, M. \& About, I. Pulp progenitor cell recruitment is selectively guided by a C5a gradient. J. Dent. Res. 92, 532-539 (2013).

19. Chmilewsky, F., About, I. \& Chung, S.-H. Pulp fibroblasts control nerve regeneration through complement activation. J. Dent. Res. 95, 913-922 (2016).

20. Chmilewsky, F., About, I., Cooper, L. F. \& Chung, S. H. C5L2 silencing in human pulp fibroblasts enhances nerve outgrowth under lipoteichoic acid stimulation. J. Endod. 44, 1396-1401 (2018).

21. Chmilewsky, F., Ayaz, W., Appiah, J., About, I. \& Chung, S.-H. Nerve growth factor secretion from pulp fibroblasts is modulated by complement $\mathrm{C} 5 \mathrm{a}$ receptor and implied in neurite outgrowth. Sci. Rep. 6, 1-10 (2016).

22. Chmilewsky, F. et al. C5L2 regulates DMP1 expression during odontoblastic differentiation. J. Dent. Res. 98, 597-604 (2019).

23. Pasiewicz, R. et al. C5a complement receptor modulates odontogenic dental pulp stem cell differentiation under hypoxia. Connect. Tissue Res. 1-10, https://doi.org/ 10.1080/03008207.2021.1924696. (2021).

24. Baldión, P. A., Velandia-Romero, M. L. \& Castellanos, J. E. Odontoblast-like cells differentiated from dental pulp stem cells retain their phenotype after subcultivation. Int. J. Cell Biol. 2018, 6853189 (2018).

25. Huang, G. T.-J., Shagramanova, K. \& Chan, S. W. Formation of odontoblast-like cells from cultured human dental pulp cells on dentin in vitro. J. Endod. 32, 1066-1073 (2006).

26. W., Cheng, et al. p38 MAP kinase-mediated odontogenic differentiation of dental pulp stem cells. Int. J. Regen. Med. 1-7, https://doi.org/10.31487/j.RGM.2020.02.03. (2020).

27. Almushayt, A., Narayanan, K., Zaki, A. \& George, A. Dentin matrix protein 1 induces cytodifferentiation of dental pulp stem cells into odontoblasts. Gene Ther. 13, 611-620 (2006).

28. Gu, K., Chang, S., Ritchie, H. H., Clarkson, B. H. \& Rutherford, R. B. Molecular cloning of a human dentin sialophosphoprotein gene. Eur. J. Oral. Sci. 108, 35-42 (2000).

29. Song, D. et al. Complement C5a receptor knockout has diminished light-induced microglia/macrophage retinal migration. Mol. Vis. 23, 210 (2017).

30. Shivakumar, K., Vidya, S. \& Chandu, G. Dental caries vaccine. Indian J. Dent. Res. 20, 99 (2009).

31. Goldberg, M. et al. Inflammatory and immunological aspects of dental pulp repair. Pharmacol. Res. 58, 137-147 (2008).

32. Sloan, A. \& Smith, A. Stimulation of the dentine-pulp complex of rat incisor teeth by transforming growth factor- $\beta$ isoforms $1-3$ in vitro. Arch. Oral. Biol. 44, 149-156 (1999).

33. Unda, F. et al. FGFs-1 and-2, and TGF $\beta 1$ as inductive signals modulating in vitro odontoblast differentiation. Adv. Dent. Res. 15, 34-38 (2001).

34. Lynch, N. J. et al. L-ficolin specifically binds to lipoteichoic acid, a cell wall constituent of Gram-positive bacteria, and activates the lectin pathway of complement. J. Immunol. 172, 1198-1202 (2004).

35. Moosig, F. et al. Reduced expression of C1q-mRNA in monocytes from patients with systemic lupus erythematosus. Clin. Exp. Immunol. 146, 409-416 (2006).

36. Ricklin, D., Hajishengallis, G., Yang, K. \& Lambris, J. D. Complement: a key system for immune surveillance and homeostasis. Nat. Immunol. 11, 785-797 (2010).

37. Berends, E. T. et al. Distinct localization of the complement $C 5 b-9$ complex on $G$ ram-positive bacteria. Cell Microbiol. 15, 1955-1968 (2013).

38. Cruvinel, W. D. M. et al. Immune system: Part I. Fundamentals of innate immunity with emphasis on molecular and cellular mechanisms of inflammatory response. Rev. Bras. Reumatol. 50, 434-447 (2010).

39. Bergmann, M., Jeanneau, C., Giraud, T., Richard, G. \& About, I. Complement activation links inflammation to dental tissue regeneration. Clin. Oral. Investig. 24, 4185-4196 (2020). 
The role of complement C5a receptor in DPSC odontoblastic differentiation... Irfan et al.

40. Vijaykumar, A. et al. Generation and characterization of DSPP-Cerulean/DMP1Cherry reporter mice. Genesis 57, e23324 (2019).

41. Matsui, M., Kobayashi, T. \& Tsutsui, T. W. CD146 positive human dental pulp stem cells promote regeneration of dentin/pulp-like structures. Hum. Cell 31, 127-138 (2018).

42. Volponi, A. A., Zaugg, L. K., Neves, V., Liu, Y. \& Sharpe, P. T. Tooth repair and regeneration. Curr. Oral. Health Rep. 5, 295-303 (2018).

43. Lim, W. H. et al. Wnt signaling regulates pulp volume and dentin thickness. J. Bone Miner. Res. 29, 892-901 (2014).

44. Gibson, M. P. et al. The rescue of dentin matrix protein 1 (DMP1)-deficient tooth defects by the transgenic expression of dentin sialophosphoprotein (DSPP) indicates that DSPP is a downstream effector molecule of DMP1 in dentinogenesis. J. Biol. Chem. 288, 7204-7214 (2013).

45. D'Souza, R. N. et al. Gene expression patterns of murine dentin matrix protein 1 (Dmp1) and dentin sialophosphoprotein (DSPP) suggest distinct developmental functions in vivo. J. Bone Miner. Res. 12, 2040-2049 (1997).

46. Botero, T. M., Shelburne, C. E., Holland, G. R., Hanks, C. T. \& Nör, J. E. TLR4 mediates LPS-induced VEGF expression in odontoblasts. J. Endod. 32, 951-955 (2006).

47. Chmilewsky, F., Jeanneau, C., Laurent, P. \& About, I. LPS induces pulp progenitor cell recruitment via complement activation. J. Dent. Res. 94, 166-174 (2015).

48. Babb, R., Chandrasekaran, D., Zaugg, L. \& Sharpe, P. Odontogenesis 111-119 (Springer, 2019).
49. Frozoni, M. et al. A feasibility study for the analysis of reparative dentinogenesis in pOBCol3. 6GFPtpz transgenic mice. Int. Endod. J. 45, 907-914 (2012).

50. Kim, Y. O. et al. Activation of intrarenal complement system in mouse model for chronic cyclosporine nephrotoxicity. Yonsei Med. J. 48, 517-525 (2007).

51. Song, M. et al. Development of a direct pulp-capping model for the evaluation of pulpal wound healing and reparative dentin formation in mice. J. Vis. Exp. 119, e54973 (2017).

(i) Open Access This article is licensed under a Creative Commons Attribution 4.0 International License, which permits use, sharing, adaptation, distribution and reproduction in any medium or format, as long as you give appropriate credit to the original author(s) and the source, provide a link to the Creative Commons license, and indicate if changes were made. The images or other third party material in this article are included in the article's Creative Commons license, unless indicated otherwise in a credit line to the material. If material is not included in the article's Creative Commons license and your intended use is not permitted by statutory regulation or exceeds the permitted use, you will need to obtain permission directly from the copyright holder. To view a copy of this license, visit http://creativecommons. org/licenses/by/4.0/.

(c) The Author(s) 2022 